\title{
Prevalence, Knowledge, and Practices of Hookah Smoking Among University Students, Florida, 2012
}

\author{
Shams Rahman, EMBA, MPH, MD; Lissette Chang, MD, MPH; Selamawit Hadgu, MPH; \\ Abraham A. Salinas-Miranda, MD, PhD; Jaime Corvin, PhD, MSPH
}

\begin{abstract}
Suggested citation for this article: Rahman S, Chang L, Hadgu S, Salinas-Miranda AA, Corvin J. Prevalence, Knowledge, and Practices of Hookah Smoking Among University Students, Florida, 2012. Prev Chronic Dis 2014;11:140099. DOI: http:// dx.doi.org/10.5888/pcd11.140099.
\end{abstract}

\section{PEER REVIEWED}

\section{Abstract}

\section{Introduction}

Although hookah smoking is becoming a source of tobacco use among college students in the United States, little is known of the students' knowledge, attitudes, and practices regarding hookah use. This cross-sectional study was aimed at determining the prevalence of hookah use and describing social and behavioral factors associated with hookah smoking among university students in a large urban university in Florida.

\section{Methods}

A convenience sample of 478 undergraduate and graduate students was recruited. Lifetime use and current use was evaluated. Logistic regression modeling was used to assess the independent association between study covariates and hookah use.

\section{Results}

Prevalence among students of having ever used hookah during their lifetime was $54.4 \%$. Hookah use within the past 30 days was $16.3 \%$. Hookah use was significantly associated with cigarette smoking (odds ratio [OR], 4.52; 95\% confidence interval [CI], 2.13-9.60) and hookah ownership (OR, 10.67; 95\% CI, 4.83-23.66) but not with alcohol use (OR, 1.73; 95\% CI, $0.74-4.04)$. Findings also suggest hookah is perceived as a safer alternative to cigarette smoking. Almost $30 \%$ of those who never smoked hookah reported they would consider smoking hookah in the future.

\section{Conclusion}

Hookah smoking is popular among college students. Misperceptions associated with hookah use indicate a starting point for developing health behavior change interventions. Future studies should investigate social and behavioral determinants of hookah use and determine the incidence of hookah use among college and high school students. Tobacco control activities should include prevention of hookah tobacco use in university settings.

\section{Introduction}

Tobacco use is the single most preventable cause of death in the United States (1). Although the 2014 Surgeon General's report, The Health Consequences of Smoking - 50 Years of Progress, indicates that the prevalence of current cigarette smoking is on the decline, the report emphasizes the need to further monitor patterns of use for all tobacco products, particularly as disparities in use persist and alternate forms of tobacco use are increasing in popularity among youths (1). Hookah tobacco smoking, for example, has increased tremendously $(2,3)$. Hookah, also known as water pipe or shisha, is a device used for smoking tobacco and other substances. Hookah smoking involves passing tobacco smoke through water before inhalation (4). In a typical 1-hour hookah smoking session, hookah users inhale approximately $90,000 \mathrm{~mL}$ volume of smoke, which is substantially more smoke than the smoke from 1 cigarette $(500-600 \mathrm{~mL})(5,6)$. The charcoal used to heat the tobacco can raise health risks by producing high levels of carbon monoxide, metals, and cancer-causing chemicals (6). One session of hookah use contains approximately 200 puffs of smoke, which exposes users to 3- to 6-fold higher levels of carbon monoxide and 46-fold higher levels of tar than from a single cigarette $(6,7)$. 
Globally more than 100 million people use hookah regularly (8). However, given the recent proliferation of hookah cafes worldwide, this estimate is likely to increase (6). In the past decade, 2,000 to 3,000 new hookah cafes opened in the United States alone (9). Until recently, few studies focused on hookah smoking, and this practice was not considered a serious health problem $(7,10)$. Although studies have begun to examine hookah use among college-aged students, the related socio-behavioral risk factors are largely unknown $(2,11)$. Reports do, however, suggest hookah smoking is increasingly popular among youths in the United States $(11,12)$. Thus, the objective of this cross-sectional study was to determine the prevalence of hookah use at a large urban university in south Florida and to describe the knowledge and practices associated with hookah use among university students.

\section{Methods}

This study used a cross-sectional survey design. Subjects were recruited from a convenience sample of students who were attending a large urban university in Florida during the 2011-12 academic year. To be eligible for participation, participants had to be enrolled as a graduate or undergraduate student at the University of South Florida (USF) during the spring 2012 semester. To assess the prevalence of hookah use, a cluster sample of 478 students was recruited. Students were asked to take a self-administered survey that included questions on demographics; current hookah smoking (defined as hookah use in the past 30 days); hookah use during their lifetime; associated risk factors; and knowledge, attitudes, beliefs, and practices regarding hookah use. Questions were designed based on a literature and expert review. Before data collection, all study instruments were field-tested with a sample of 20 students and revised on the basis of the test results.

To determine the required size for the overall sample and to calculate cluster sizes (one-stage cluster sampling), we used the Centers for Disease Control and Prevention's EpiInfo v.6 Statistical Calculator's "population study option" (parameters: total population size, expected frequency, and worst acceptable). More than 30 natural clusters were sampled, including all the university's colleges, 2 libraries, the student center, on-campus dormitories, and the fitness center. The study was reviewed and approved by the university's institutional review board. All data were analyzed in SAS 9.3 (SAS Institute Inc). First, demographic characteristics of hookah users and nonusers were compared using $\chi^{2}$ and Fisher exact tests. Current and lifetime use prevalence was evaluated for the entire sample and subgroups. Finally, unadjusted and adjusted analyses using logistic regression modeling were conducted to identify associated factors for hookah use. Analysis results were adjusted for age, sex, education, cigarette smoking, alcohol use, owning a personal hookah, having a friend who smoked hookah, and proximity to hookah lounges.

\section{Results}

\section{Sample description}

In total, 478 participants were interviewed, of which 261 were women (54.6\%) and 217 were men (45.4\%) (Table 1), a ratio consistent with the university's enrollment in 2011-12 (women, 56\%; men, $\left.44 \% ; \chi^{2} P=.540\right)$. Most (78.8\%) were undergraduate students, a finding also consistent with the USF enrollment (undergraduate, $74 \%$; graduate/postgraduate, $22 \% ; \chi^{2} P=.781$ ). Participants were of varied ethnicities including white (33.4\%), Asian $(21.3 \%)$, Hispanic (17.4\%), and black (12.8\%). The sample ethnicity was statistically different $(P=.001)$ from the university's enrollment in $2011-12$, which was reported as white $(60 \%)$, Hispanic (17\%), Asian (6\%), and black (11\%).

\section{Current and lifetime prevalence of hookah smoking}

Current prevalence of hookah use was $16.3 \%$ (95\% CI, 13.0-19.7) (Table 2). More men than women reported current hookah use ( $22.2 \%$ men vs $11.5 \%$ women). Students of Middle Eastern descent reported the highest prevalence of current hookah use (24.4\%), followed by white (17.3\%), Asian (16.3\%), Hispanic (12.5\%), and African American (3.6\%) students. There was no difference in the prevalence of hookah smoking between undergraduate $(15.6 \%)$ and graduate $(15.8 \%)$ students.

The prevalence of lifetime (ever use) of hookah in our sample was $54.4 \%$ (95\% CI, 50.0-58.9) with $49.4 \%$ of women and $60.6 \%$ of men reporting ever using a hookah. Lifetime use by race/ethnicity was $68.2 \%$ for white students, $62.0 \%$ for Hispanic students, $53.5 \%$ for Middle Eastern students, $42.3 \%$ for Asian students, $28.8 \%$ for African American students, and $20.0 \%$ for Native American students. Lifetime use among undergraduates was $53.8 \%$ and among graduates was $54.1 \%$. Additionally, prevalence of lifetime use was 2 -fold higher among participants who owned a private hookah (96.2\%) than among those who did not (49.5\%).

\section{Knowledge, attitudes, and practices of hookah smoking}

When shown a picture of a standard hookah, most (95.8\%) participants recognized the image. When asked about the harmfulness of hookah smoking, $74.6 \%$ indicated that hookah smoking is harmful for health. However, $12.6 \%$ reported hookah smoking was not harmful, and $12.8 \%$ reported they were unsure of the harmfulness. Most (50.6\%) participants also indicated that cigarette

\footnotetext{
The opinions expressed by authors contributing to this journal do not necessarily reflect the opinions of the U.S. Department of Health and Human Services, the Public Health Service, the Centers for Disease Control and Prevention, or the authors' affiliated institutions.
} 
smoking is more dangerous than hookah smoking. When asked to identify the sources from which they received information on hookah harmfulness, participants cited no formal means of acquiring data about hookah safety or harm; they instead reported using their own judgment $(70.3 \%)$ or acquiring information from friends $(25.9 \%)$ or the Internet $(22.4 \%)$. When asked about the presence of hookah bars or lounges, $92.2 \%$ of participants reported having a hookah bar or lounge within a 10 -mile radius of their residential area.

Those who had not smoked hookah were asked if they would ever consider hookah smoking in the future. Almost 30\% reported they would. Of those who reported they would consider hookah smoking in the future, reasons cited for this were the time together with friends, the fun associated with the activity, the pleasant atmosphere, the social acceptability, and the perception that hookah smoking was a healthier alterative to cigarette use.

Most (85.3\%) respondents reported having a friend who smokes hookah. More than $30 \%$ of the sample reported having a friend who owns a hookah, while $11 \%$ of respondents reported owning one themselves. Current hookah usage was 6-fold higher among participants who owned a private hookah (60.8\%) when compared with those who did not (11.0\%). Also, prevalence of current hookah use was 4-fold higher among cigarette smokers $(45.6 \%)$ than among those who did not smoke cigarettes (11.3\%).

Current hookah users were asked how often they smoke hookah in a given month. Most (55.3\%) reported smoking hookah once in a month, with fewer smoking hookah twice a week $(19.7 \%)$, once a week $(19.7 \%)$, or every day $(5.3 \%)$. When asked about length of exposure, almost half of current hookah smokers reported smoking hookah for longer than 1 hour per session, with $32.4 \%$ smoking for 61 to 120 minutes and $13.5 \%$ smoking greater than 120 minutes per session. Another $40.5 \%$ of participants reported spending between 30 and 60 minutes a session and $13.5 \%$ reported smoking for less than 30 minutes.

\section{Factors associated with hookah smoking}

Unadjusted and adjusted logistic regression modeling was conducted to determine the independent association between socio-demographic factors and hookah use as well as knowledge, attitudes, and practices regarding hookah smoking (Table 3). In unadjusted analysis, sex and race were significantly associated with increased odds of hookah smoking. Men were 2.2 times more likely than women to use hookah (odds ratio [OR], 2.2; 95\% confidence interval [CI], 1.33-3.64). When compared with whites, African Americans (OR, 0.18; 95\% CI, 0.04-0.77) had significantly lower risk of hookah smoking; the lower risk among Hispanics (OR, 0.68; 95\% CI, 0.31-1.50) was insignificant. The increased risk among Middle Easterners (OR, 1.05; 95\% CI, 0.56-1.96) was not significant.

Cigarette smoking, alcohol use, hookah ownership, and having a friend who uses hookah were other significant risk factors in the unadjusted model. However, in the adjusted model, only cigarette smoking and hookah ownership remained significantly associated with hookah use (controlling for sex, alcohol use, having friends who use hookah, and having a hookah bar or lounge within 10 miles of one's residence). Specifically, cigarette smokers were 4.52 times more likely than nonsmokers to use hookah. Moreover, hookah ownership increased 10.67-fold the risk of hookah use.

\section{Discussion}

Findings from our study suggest the current prevalence of hookah use among college students at USF is $16.3 \%$. This rate is consistent with prevalence studies conducted with college-aged youths $(11,13,14)$. Findings are also consistent with those of other studies, including higher rates of smoking among men than among women, higher prevalence among non-Hispanic whites than among other races, and higher prevalence among smokers than among nonsmokers $(13,14)$. The prevalence of ever using hookah $(54.4 \%)$ found in our study was higher than estimates reported by Fielder and colleagues (15) in New York (about 45\%) and by Smith and colleagues (14) in California (about 25\%).

The value of our study lies in the descriptive nature of the knowledge, attitudes, and practices of the current student population, which shed light for potential preventive actions in university settings. In particular, our study indicates 2 important factors that must be addressed to curtail hookah smoking: the social nature of hookah use and misperceptions regarding risk and harmfulness of hookah smoking reported by nearly a quarter of our sample. Other studies pointed to the importance of these factors as predictors of increased prevalence of hookah smoking during college $(11,14)$. However, specific interventions are needed to dispel each different belief of the population at risk. For instance, most respondents acknowledged that hookah smoking has harmful effects, findings consistent with other studies (10). Yet more than half of the sample believed hookah smoking to be a safer alternative to cigarette smoking and, regardless of their perception of harmfulness, almost a third of the sample reported they would consider hookah smoking in the future. This finding suggests that knowledge regarding the harmful effects of hookah use may not be the most substantial barrier to preventing hookah smoking and that correct-

The opinions expressed by authors contributing to this journal do not necessarily reflect the opinions of the U.S. Department of Health and Human Services, the Public Health Service, the Centers for Disease Control and Prevention, or the authors' affiliated institutions. 
ing the misperception of hookah as a safer alternative may be a more appropriate target for health education efforts. Further investigations into risk factors for hookah smoking initiation and continuation are needed (14).

The reasons why individuals believe hookah smoking is a safer alternative to cigarette smoking are unclear. However, there is no evidence that the effects of the tobacco are less serious if a water pipe is used (16). In our study, more than half of the sample perceived cigarette smoking as more dangerous than hookah smoking. Yet data suggest that hookah smoking, because of higher levels of carbon monoxide and tar, poses a considerably greater health hazard than cigarette smoking $(6,9)$. Because of the filtration mechanism, smoke that emits from a hookah is softer and lighter and has a more pleasant smell than smoke emitted from a cigarette. This may lead smokers to a false belief that hookah smoking is safe or harmless (17). Traditional antitobacco campaigns focus on cigarettes, cigars, and smokeless tobacco with little to no attention to hookah or other nicotine delivery systems, potentially further spreading this false belief.

One notable reason that students consider hookah smoking is the social nature of the activity, which may be a difficult barrier for health education programs to overcome. Hookah smoking brings with it numerous challenges not combated by previous antismoking campaigns, including the social aspect of relaxing with friends and the fun associated with this activity. The high rate of hookah device ownership in our study suggests that hookah smoking may be moving from an occasional activity to a regular habit. However, we could not find studies conducted in the same setting with which to compare our study findings. In Florida, efforts have been made to track tobacco use (including hookah) among high school students through population-based surveys (18), but data for college students are not gathered. Efforts are beginning at the national level to track tobacco use (including hookah) among college students in the United States, but institutionally based studies are scarce. The absence of local data is a limitation for direct local action. This situation should prompt universities to monitor alternative forms of tobacco use, including hookah, e-cigarettes, and emerging alternatives, in local student health assessments.

Our findings suggest the need for population-based studies to examine unintended effects of current regulations on alternative forms of tobacco use. For instance, although Florida's Clean Indoor Air Act regulates "any lighted tobacco product," (19) many hookah lounges are licensed as retail tobacco stores, exempting them from the act. This loophole in the law creates the appearance that hookah smoking may be permitted in places where cigarette and cigar smoking is prohibited, which may be perceived as ac- knowledgment that hookah smoking is safe for the public. Under current regulations, hookah can be purchased from a hookah lounge or an online shop without age restriction and hookah products are widely available in convenience stores at lower prices than cigarettes, making hookah an available and viable alternative to cigarettes. Additionally, the lack of regulations on the proximity of hookah smoking cafés to university settings is also concerning. Some have recommended regulations to prevent hookah establishments from operating near high schools or colleges, enforcement of strict identity checks, and the taxing of hookah products as potential ways to combat the rising trends in hookah use $(12,20)$. More studies, both qualitative and quantitative, are needed to examine the role of popular media in promoting new hookah establishments near universities to evaluate whether hookah is being portrayed as a "healthy" alternative to smoking.

As with any research initiative, this study is not without limitation. Although numerous instruments for measuring hookah use have been reported (21), we could not find a standardized tool available to estimate the prevalence of hookah use. Thus, our instrument was designed based on available data in the literature. Although this study makes an important step in developing such a tool (ie, our instrument was pre-piloted, piloted, and field tested, and revised multiple times before data collection), assessment of factorial validity and cross-validation in large samples was outside the scope of our study. Future studies should attempt to assess the psychometric properties of available research instruments on larger samples. Another limitation is the cross-sectional nature of our data. Specifically, our findings suggest cigarette smoking is associated with hookah use. However, because of the cross-sectional data, such association should be taken with caution and must be further explored in longitudinal studies that can characterize risk more appropriately. More studies are needed to understand the link between cigarette usage and hookah usage. Future studies should compare the frequency and intensity of usage between hookah and cigarette smoking. For instance, we were not able to assess whether students were substituting cigarette use with hookah use or whether they were using both smoking methods in tandem. Cigarette smokers may indeed constitute a high-risk group for hookah smoking, in which case additional efforts should be aimed at cigarette smokers to increase their awareness of the harmfulness of all alternative smoking mechanisms, including hookah. Conversely, hookah smoking may be a gateway for smoking. Our data do not permit such distinction, and we recommend that panel studies be conducted in university settings to uncover why prevalence changes are occurring. Future studies should attempt to disentangle the relationship between concurrent cigarette smoking and hookah use. Because of the cross-sectional nature of the data and the lack of comparison data from previous

The opinions expressed by authors contributing to this journal do not necessarily reflect the opinions of the U.S. Department of Health and Human Services, the Public Health Service, the Centers for Disease Control and Prevention, or the authors' affiliated institutions. 
years, we could not assess trends. Because current trends in water pipe use in other universities indicate that water pipe use is increasing among college students $(11,14,22)$, future studies must attempt to examine hookah usage longitudinally and by year in university.

Our findings indicate a need to monitor knowledge, attitudes, and practices related to hookah use among college students. Misperceptions associated with hookah use are a starting point for the development of health behavior change interventions. On the basis of our findings, we recommend that public health messaging consider misperceptions regarding hookah use as a safe alternative to cigarettes and target youths and college students as well as the general public. Educational campaigns must be designed to address misunderstandings regarding risks associated with hookah smoking and should be inclusive of other recreational tobacco use and nicotine delivery devices, including e-cigarettes, e-hookah, and other emerging devices, as well as the regulation of sales and marking of these devices. Future studies should attempt to gain a deeper understanding of the social and behavioral determinants of hookah use and determine the incidence of hookah use in representative samples of college and high school students. Tobacco control activities should include prevention of water pipe tobacco use in university settings.

\section{Acknowledgments}

The data presented in this article are from an unfunded study conducted at USF. The authors thank the students in Dr Corvin's Global Health Assessment Strategies course at the USF College of Public Health, who supported this research and helped with the first pilot of the instruments.

\section{Author Information}

Corresponding Author: Jaime Corvin, PhD, MSPH, CPH, 13201 Bruce B. Downs Blvd, MDC 56, Tampa, FL 33612. Telephone: 813-974-6690. E-mail: jcorvin1@health.usf.edu.

Author Affiliations: Shams Rahman, Lissette Chang, Selamawit Hadgu, Abraham A. Salinas-Miranda, University of South Florida, Tampa, Florida.

\section{References}

1. US Department of Health and Human Services. The health consequences of smoking - 50 years of progress: a report of the Surgeon General. Atlanta (GA): US Department of Health and Human Services, Centers for Disease Control and Prevention, National Center for Chronic Disease Prevention and Health Promotion, Office on Smoking and Health; 2014. http://www.cdc.gov/tobacco/data_statistics/sgr/50thanniversary/index.htm. Accessed June 11, 2014.

2. Maziak W. The global epidemic of waterpipe smoking. Addict Behav 2011;36(1-2):1-5.

3. Maziak W. The waterpipe: an emerging global risk for cancer. Cancer Epidemiol 2013;37(1):1-4.

4. World Health Organization. Waterpipe tobacco smoking: health effects, research needs and recommended actions by regulators; 2005. http://www.who.int/tobacco/ g 1 o b a $1_{\text {_ }}$ i n t e r a c t i o n/to b r e g / Waterpipe\%20recommendation_Final.pdf. Accessed October 8, 2013.

5. Centers for Disease Control and Prevention. Smoking and tobacco use: hookahs. 2013. http://www.cdc.gov/tobacco/ data_statistics/fact_sheets/tobacco_industry/hookahs. Accessed October 8, 2013.

6. Cobb C, Ward KD, Maziak W, Shihadeh AL, Eissenberg T. Waterpipe tobacco smoking: an emerging health crisis in the United States. Am J Health Behav 2010;34(3):275-85.

7. Barnett TE, Curbow BA, Soule EKJr, Tomar SL, Thombs DL. Carbon monoxide levels among patrons of hookah cafes. Am J Prev Med 2011;40(3):324-8.

8. Wolfram RM, Chehne F, Oguogho A, Sinzinger H. Narghile (water pipe) smoking influences platelet function and (iso)eicosanoids. Life Sci 2003;74(1):47-53.

9. American Lung Association. Tobacco policy trend alert: an emerging deadly trend: waterpipe tobacco use; 2007. http:// www.lungusa2.org/embargo/slati/Trendalert_Waterpipes.pdf. Accessed October 8, 2014.

10. Ahmed B, Jacob P3d, Allen F, Benowitz N. Attitudes and practices of hookah smokers in the San Francisco Bay Area. J Psychoactive Drugs 2011;43(2):146-52.

11. Sutfin EL, McCoy TP, Reboussin BA, Wagoner KG, Spangler J, Wolfson M. Prevalence and correlates of waterpipe tobacco smoking by college students in North Carolina. Drug Alcohol Depend 2011;115(1-2):131-6.

12. Griffiths MA, Harmon TR, Gilly MC. Hubble bubble trouble: the need for education about and regulation of hookah smoking. Journal of Public Policy and Marketing 2011; 30(1):119-32.

13. Al-Delaimy WK, White MM, Mills AL, Pierce JP, Emory K, Boman M, et al.Two decades of the California Tobacco Control Program: California Tobacco Survey, 1990-2008. University of California, San Diego. 2010. http:// www.cdph.ca.gov/programs/tobacco/Documents/Resources/ $\begin{array}{lllllllllllll}\mathrm{P} & \mathrm{u} & \mathrm{b} & \mathrm{l} & \mathrm{i} & \mathrm{c} & \mathrm{a} & \mathrm{t} & \mathrm{i} & \mathrm{o} & \mathrm{n} & \mathrm{s} & /\end{array}$ CDPH_CTS2008\%20summary\%20report_final.pdf. Accessed October 8, 2013.

The opinions expressed by authors contributing to this journal do not necessarily reflect the opinions of the U.S. Department of Health and Human Services, the Public Health Service, the Centers for Disease Control and Prevention, or the authors' affiliated institutions. 
14. Smith JR, Edland SD, Novotny TE, Hofstetter CR, White MM, Lindsay SP, et al. Increasing hookah use in California. Am J Public Health 2011;101(10):1876-9.

15. Fielder RL, Carey KB, Carey MP. Prevalence, frequency, and initiation of hookah tobacco smoking among first-year female college students: a one-year longitudinal study. Addict Behav 2012;37(2):221-4.

16. Jukema JB, Bagnasco DE, Jukema RA. Waterpipe smoking: not necessarily less hazardous than cigarette smoking: possible consequences for (cardiovascular) disease. Neth Heart J 2014; 22(3):91-9.

17. Martinasek MP, McDermott RJ, Martini L. Waterpipe (hookah) tobacco smoking among youth. Curr Probl Pediatr Adolesc Health Care 2011;41(2):34-57.

18. Florida Department of Health. Florida Youth Tobacco Survey: 2013 Florida Youth Tobacco Survey reports. 2013. http:// www.floridahealth.gov/reports-and-data/survey-data/fl-youthtobacco-survey/reports/2013-state/index.html. Accessed March 2, 2014.

19. Florida Department of Health. Florida Clean Indoor Air Act. Florida Department of Health and Department of Business and Professional Regulation; 2003. http://www.floridahealth.gov/ healthy-environments/indoor-air-quality/indoor-air-act/ index.html. Accessed December 9, 2013.

20. American Lung Association. Hookah smoking: a growing threat to public health; 2011. http://www.lung.org/stopsmoking/tobacco-control-advocacy/reports-resources/ cessation-economic-benefits/reports/hookah-policy-brief.pdf. Accessed October 8, 2013.

21. Akl EA, Aleem S, Gunukula SK, Honeine R, Abou Jaoude P, Irani J. Survey instruments used in clinical and epidemiological research on waterpipe tobacco smoking: a systematic review. BMC Public Health 2010;10:415.

22. Enofe N, Berg CJ, Nehl EJ. Alternative tobacco use among college students: who is at highest risk? Am J Health Behav 2014;38(2):180-9.

\footnotetext{
The opinions expressed by authors contributing to this journal do not necessarily reflect the opinions of the U.S. Department of Health and Human Services, the Public Health Service, the Centers for Disease Control and Prevention, or the authors' affiliated institutions.
} 


\section{Tables}

Table 1. Characteristics of University Students Surveyed About Prevalence, Knowledge, and Practices of Hookah Smoking, Florida, $2012^{a}$

\begin{tabular}{|c|c|c|c|c|}
\hline Characteristics & $\begin{array}{c}\text { Total Population ( } n= \\
478), n(\%)\end{array}$ & $\begin{array}{c}\text { Hookah Use }(n=76) \\
n(\%)\end{array}$ & $\begin{array}{c}\text { No Hookah Use }(n= \\
389), n(\%)\end{array}$ & $P$ Value $^{\mathrm{b}}$ \\
\hline \multicolumn{5}{|l|}{ Sex } \\
\hline Female & $261(54.6)$ & $29(11.5)$ & $224(88.5)$ & \multirow{2}{*}{.002} \\
\hline Male & $217(45.4)$ & $47(22.2)$ & $165(77.8)$ & \\
\hline \multicolumn{5}{|l|}{ Ethnicity } \\
\hline White & $154(33.4)$ & $26(17.3)$ & $124(82.7)$ & \multirow{7}{*}{.081} \\
\hline Asian & $98(21.3)$ & $16(16.3)$ & $82(83.7)$ & \\
\hline Hispanic/Latino & $80(17.4)$ & $10(12.5)$ & $70(87.5)$ & \\
\hline African American/Black & $59(12.8)$ & $2(3.6)$ & $54(96.4)$ & \\
\hline Middle Eastern & $45(9.8)$ & $10(24.4)$ & $31(75.6)$ & \\
\hline Native American & $5(1.1)$ & $1(20.0)$ & $4(80.0)$ & \\
\hline Other & $20(4.2)$ & $5(26.3)$ & $14(73.7)$ & \\
\hline \multicolumn{5}{|l|}{ Age, y } \\
\hline$\leq 20$ & $208(44.2)$ & $40(19.6)$ & $164(80.4)$ & \multirow{2}{*}{.429} \\
\hline$\geq 21$ & $263(55.8)$ & $35(13.7)$ & $221(86.3)$ & \\
\hline \multicolumn{5}{|l|}{ Study program } \\
\hline Undergraduate & $372(78.8)$ & $57(15.6)$ & $308(84.4)$ & \multirow{2}{*}{.967} \\
\hline Graduate & $100(21.2)$ & $15(15.8)$ & $80(84.2)$ & \\
\hline \multicolumn{5}{|l|}{ Cigarette use } \\
\hline Yes & $69(14.6)$ & $31(45.6)$ & $37(54.4)$ & \multirow{2}{*}{$<.001$} \\
\hline No & $402(85.4)$ & $45(11.3)$ & $352(88.7)$ & \\
\hline \multicolumn{5}{|l|}{ Alcohol use } \\
\hline Yes & $285(60.9)$ & 56 (19.9) & $225(80.1)$ & \multirow{2}{*}{.007} \\
\hline No & $183(39.1)$ & $19(10.4)$ & $163(89.6)$ & \\
\hline \multicolumn{5}{|l|}{ Hookah ownership } \\
\hline Owns hookah & $52(11.0)$ & $31(60.8)$ & $20(39.2)$ & \multirow{2}{*}{$<.001$} \\
\hline Does not own hookah & $421(89.0)$ & $45(11.0)$ & $366(89.0)$ & \\
\hline \multicolumn{5}{|l|}{ Friends use hookah } \\
\hline Yes & $367(85.3)$ & $74(20.8)$ & $282(79.2)$ & \multirow{2}{*}{$<.001$} \\
\hline No & $63(14.7)$ & $1(1.6)$ & $61(98.4)$ & \\
\hline
\end{tabular}

a Missing observations not included in the analyses.

b $P$ values $<.01$ are considered significant.

The opinions expressed by authors contributing to this journal do not necessarily reflect the opinions of the U.S. Department of Health and Human Services, the Public Health Service, the Centers for Disease Control and Prevention, or the authors' affiliated institutions. 
Table 2. Prevalence of Current and Lifetime Hookah Use Among University Students, Florida, 2012

\begin{tabular}{|c|c|c|c|}
\hline Characteristics & Total Sample, N (\%) & Current Hookah Use, $\%(95 \% \mathrm{Cl})$ & Lifetime Hookah Use, \% (95\% Cl) \\
\hline Overall sample & $478(100)$ & $16.3(13.0-19.7)$ & $54.4(50.0-58.9)$ \\
\hline \multicolumn{4}{|l|}{ Sex } \\
\hline Female & $261(54.6)$ & $11.5(7.5-15.4)$ & $49.4(43.3-55.5)$ \\
\hline Male & $217(45.4)$ & $22.2(16.6-27.8)$ & $60.6(54.0-67.1)$ \\
\hline \multicolumn{4}{|l|}{ Race } \\
\hline White & $154(33.4)$ & $17.3(11.3-23.4)$ & $68.2(60.8-75.5)$ \\
\hline Asian & $98(21.3)$ & $16.3(9.0-23.6)$ & $42.3(32.4-52.1)$ \\
\hline Hispanic/Latino & $80(17.4)$ & $12.5(5.2-19.8)$ & $62.0(51.3-72.7)$ \\
\hline African American/black & $59(12.8)$ & $3.6(0.4-12.3)$ & $28.8(17.8-42.1)$ \\
\hline Middle Eastern & $45(9.8)$ & $24.4(11.2-37.5)$ & $53.5(38.6-68.4)$ \\
\hline Native American & $5(1.1)$ & $20.0(0.5-71.6)$ & $20.0(0.5-71.6)$ \\
\hline Others & $20(4.3)$ & $26.3(6.5-46.1)$ & $55.0(33.2-76.8)$ \\
\hline \multicolumn{4}{|l|}{ Study program } \\
\hline Undergraduate & $372(78.8)$ & $15.6(11.9-19.3)$ & $53.8(48.7-58.9)$ \\
\hline Graduate & $100(21.2)$ & $15.8(8.5-23.1)$ & $54.1(44.2-64.0)$ \\
\hline \multicolumn{4}{|l|}{ Friends use hookah } \\
\hline Yes & $367(85.3)$ & $20.8(16.6-25.0)$ & $61.1(56.0-66.1)$ \\
\hline No & $63(14.7)$ & $1.6(0.04-8.7)$ & $39.7(27.6-51.8)$ \\
\hline \multicolumn{4}{|c|}{ Hookah lounge within 10 miles of residence } \\
\hline Present & $379(92.2)$ & $18.9(14.9-22.9)$ & $60.4(55.4-65.3)$ \\
\hline Not present & $32(7.8)$ & $13.3(1.2-25.5)$ & $41.9(24.6-59.3)$ \\
\hline \multicolumn{4}{|l|}{ Hookah ownership } \\
\hline Owns hookah & $52(11.0)$ & $60.8(47.4-74.2)$ & $96.2(86.8-99.5)$ \\
\hline Does not own hookah & $421(89.0)$ & $11.0(7.9-143.0)$ & $49.5(44.7-54.3)$ \\
\hline \multicolumn{4}{|l|}{ Cigarette use } \\
\hline Yes & $69(14.6)$ & $45.6(33.8-57.4)$ & $91.3(84.7-98.0)$ \\
\hline No & $402(85.4)$ & $11.3(8.2-14.4)$ & $48.7(43.8-53.6)$ \\
\hline \multicolumn{4}{|l|}{ Alcohol use } \\
\hline Yes & $285(60.9)$ & $19.9(15.3-24.6)$ & $68.1(62.7-73.5)$ \\
\hline No & $183(39.1)$ & $10.4(6.0-14.9)$ & $34.6(27.7-41.6)$ \\
\hline
\end{tabular}

Abbreviation: $\mathrm{Cl}$, confidence interval.

The opinions expressed by authors contributing to this journal do not necessarily reflect the opinions of the U.S. Department of Health and Human Services, the Public Health Service, the Centers for Disease Control and Prevention, or the authors' affiliated institutions. 
Table 3. Factors Associated With Hookah Use Among University Students $(n=478)$, Florida, 2012

\begin{tabular}{|c|c|c|}
\hline Characteristics & OR $(95 \% \mathrm{Cl})$ & AOR (95\% Cl) \\
\hline Age & $0.97(0.90-1.04)$ & $0.94(0.81-1.01)$ \\
\hline \multicolumn{3}{|l|}{ Sex } \\
\hline Male & $2.20(1.33-3.64)$ & $1.60(0.84-3.08)$ \\
\hline Female & 1 [Reference] & 1 [Reference] \\
\hline \multicolumn{3}{|l|}{ Race } \\
\hline African American/black & $0.18(0.04-0.77)$ & $0.46(0.08-2.69)$ \\
\hline Hispanic/Latino & $0.68(0.31-1.50)$ & $0.75(0.28-1.97)$ \\
\hline Middle Eastern & $1.05(0.56-1.96)$ & $0.97(0.29-3.26)$ \\
\hline Other & $1.54(0.67-3.52)$ & $1.69(0.75-3.81)$ \\
\hline White & 1 [Reference] & 1 [Reference] \\
\hline \multicolumn{3}{|l|}{ Study program } \\
\hline Undergraduate & $0.99(0.53-1.83)$ & $0.49(0.17-1.39)$ \\
\hline Graduate & 1 [Reference] & 1 [Reference] \\
\hline \multicolumn{3}{|l|}{ Cigarette use } \\
\hline Yes & $6.55(3.71-11.58)$ & $4.52(2.13-9.60)$ \\
\hline No & 1 [Reference] & 1 [Reference] \\
\hline \multicolumn{3}{|l|}{ Alcohol use } \\
\hline Yes & $2.14(1.22-3.73)$ & $1.73(0.74-4.04)$ \\
\hline No & 1 [Reference] & 1 [Reference] \\
\hline \multicolumn{3}{|l|}{ Hookah ownership } \\
\hline Owns hookah & $12.61(6.64-23.95)$ & $10.67(4.83-23.66)$ \\
\hline Does not own hookah & 1 [Reference] & 1 [Reference] \\
\hline \multicolumn{3}{|l|}{ Friends use hookah } \\
\hline Yes & $16.00(2.18-117.37)$ & $7.44(0.83-67.01)$ \\
\hline No & 1 [Reference] & 1 [Reference] \\
\hline \multicolumn{3}{|c|}{ Hookah lounge within 10 miles of residence } \\
\hline Present & $1.52(0.51-4.49)$ & $1.25(0.28-5.47)$ \\
\hline Not present & 1 [Reference] & 1 [Reference] \\
\hline
\end{tabular}

Abbreviations: OR, odds ratio; $\mathrm{Cl}$, confidence interval; AOR, adjusted odds ratio. 